\title{
Algorithm for Recanalization of Chronic Totally Occluded (CTO) Native Coronary Arteries Through a Diseased or Occluded Saphenous Vein Graft in Post Bypass Patients.
}

\author{
Ief Hendrickx ${ }^{1}$, Bert Ferdinande ${ }^{1}$, Colm Hanratty ${ }^{2}$, Jo Dens ${ }^{*}$, \\ ${ }^{1}$ Department of interventional cardiology, Ziekenhuis Oost-Limburg, Genk, Belgium \\ ${ }^{2}$ Department of interventional cardiology, Belfast City Hospital, Belfast, United Kingdom
}

*Corresponding Author: Jo Dens, MD, PhD Department of interventional cardiology Ziekenhuis Oost-Limburg Schiepse bos 6, 3600 Genk, Belgium

Received Date: January 27, 2021 ; Accepted Date: February 02, 2021; Published Date: February 09, 2021

Citation: Ief Hendrickx, Bert Ferdinande, Colm Hanratty, Jo Dens, (2021) Algorithm for Recanalization of Chronic Totally Occluded (CTO) Native Coronary Arteries Through a Diseased or Occluded Saphenous Vein Graft in Post Bypass Patients.. J. Clinical Cardiology and Cardiovascular Interventions, 4(2); Doi:10.31579/2641-0419/134

Copyright: (c) 2021 Jo Dens, This is an open-access article distributed under the terms of the Creative Commons Attribution License, which permits unrestricted use, distribution, and reproduction in any medium, provided the original author and source are credited.

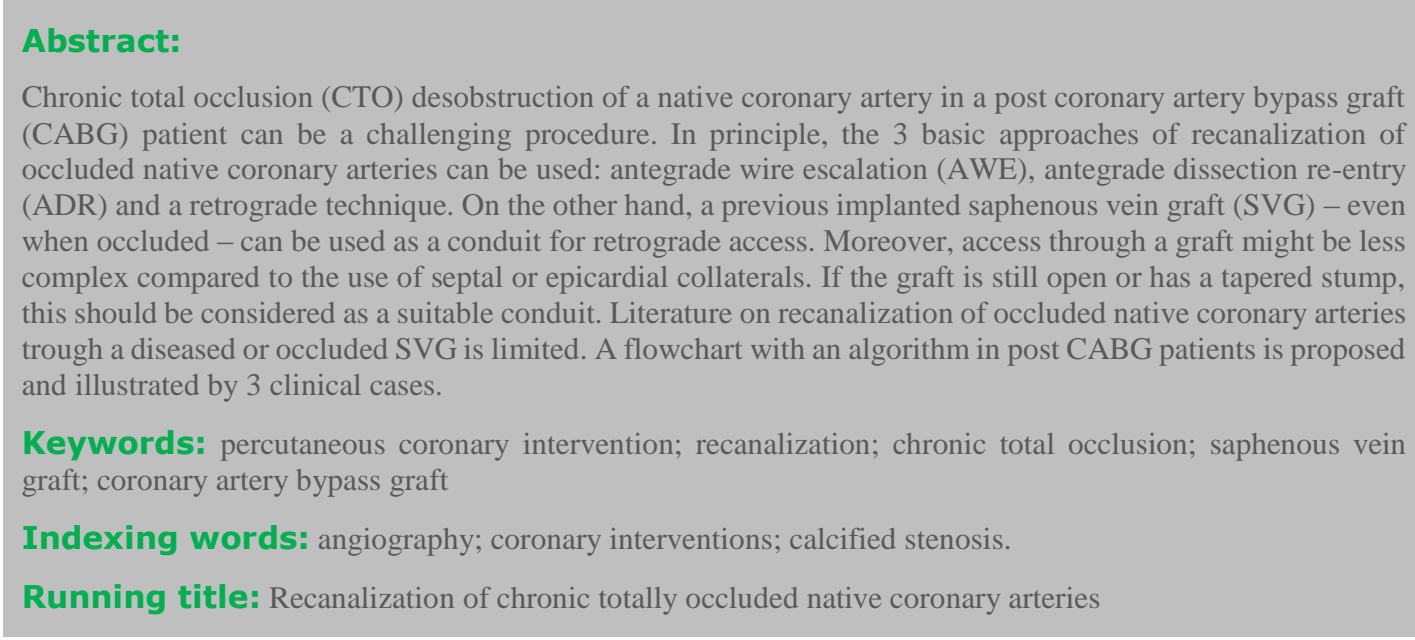

\section{Introduction}

About 30 years ago, Kahn and Hartzler performed the first percutaneous coronary intervention (PCI) through a saphenous vein graft (SVG) on a native coronary artery [1]. Although these landmark procedures were done a long time ago and many has changed regarding techniques and available materials, chronic total occlusion (CTO) desobstruction of a native coronary artery in a post coronary artery bypass graft (CABG) patient remains a challenging procedure $[2,3]$.

Recanalization of an occluded coronary artery, by using a retrograde approach has significantly improved procedural success rates [4,5]. The most common retrograde conduits are septal collaterals followed by epicardial collaterals. Diseased or occluded SVGs are also suitable for retrograde access in CABG patients, but literature on these procedures is limited.

CTO desobstruction of a native coronary artery which is bypassed by a diseased or occluded SVG can be performed by the three conventional techniques: antegrade wire escalation (AWE), antegrade dissection reentry (ADR) and by a retrograde technique (Figure 1). 


\section{General approach}

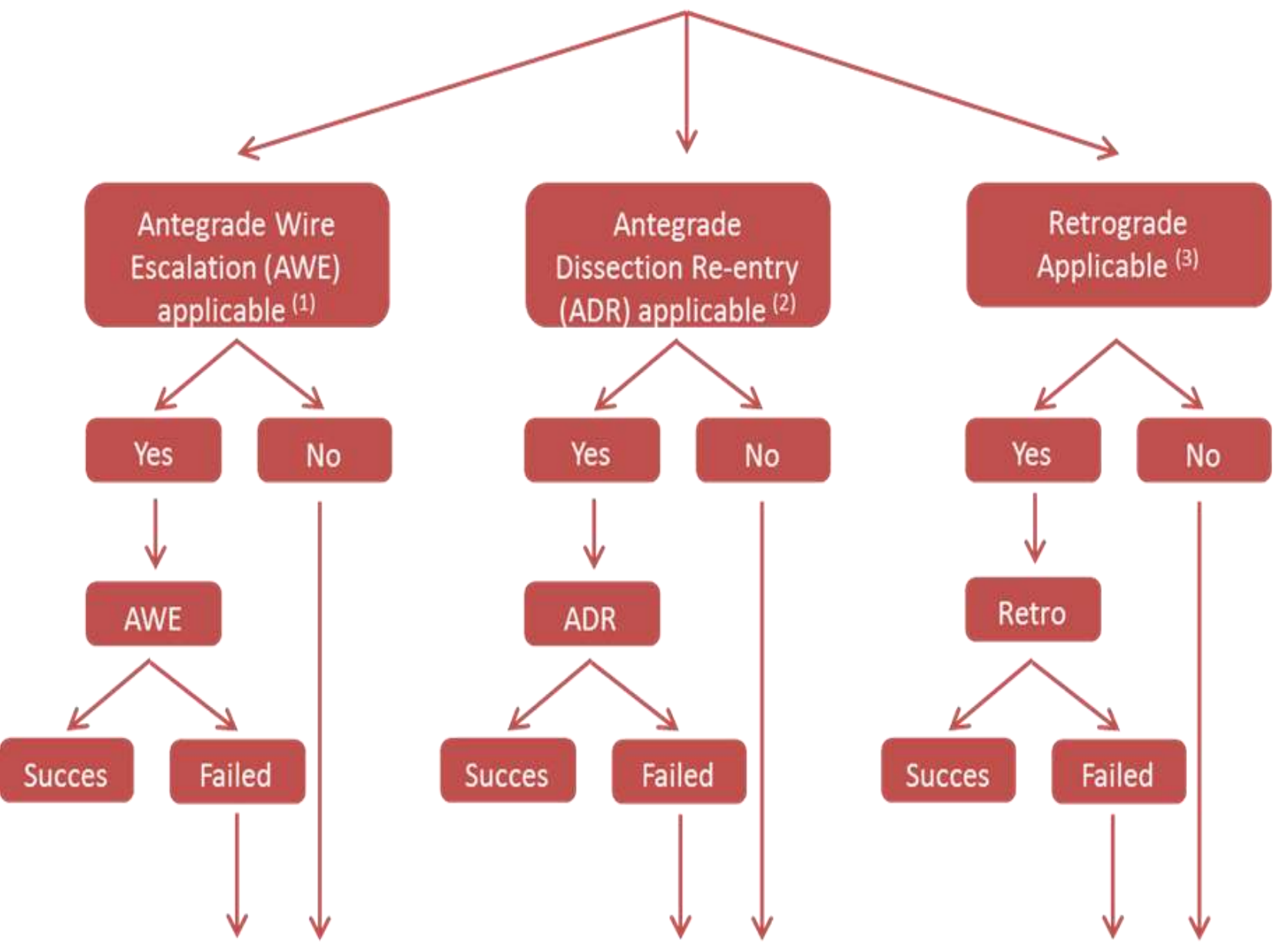

\section{Switch to other conventional strategy (AWE, ADR, Retro,...) \\ or proceed through the diseased/occluded saphenous vein graft}

(1) Non-ambiguous cap

Lesion length $<20 \mathrm{~mm}$
(2) Non-ambiguous cap

Lesion length $>20 \mathrm{~mm}$

Appropiate landing zone
(3) Ambiguous cap

Suitable interventional collaterals/crossed graft

Figure 1: General strategy ( $A W E=$ antegrade wire escalation, $A D R=$ antegrade dissection re-entry)

In function of the lesion characteristics (ambiguous or non-ambiguous cap, occlusion length and quality of the landing zone) different techniques are applied. AWE is mainly used in short lesions ( $<20 \mathrm{~mm}$ length) with a non-ambiguous cap. ADR is mainly used in longer lesions ( $>20 \mathrm{~mm}$ length) with a non-ambiguous cap and an appropriate landing zone, whereas a retrograde technique is preferred for lesions with an ambiguous cap in the presence of suitable interventional collaterals (septal or epicardial) or graft (both arterial and venous). If present, SVG gain preference above septal and epicardial collaterals because of easier crossability, less tortuosity, larger caliber and less risk of perforation [6]. In case the SVG is occluded, usually the distal segment is visualized by collaterals. In case a retrograde approach is needed, access through the diseased or even occluded SVG is an additional option (Figure 2), especially when the collaterals are poorly developed or non-suitable for crossing with a wire or a microcatheter. If the graft is still open or diseased (with tapered stump), this graft should be considered as a suitable conduit and therefore can be used as for facilitated ADR. 
Diseased saphenous vein graft

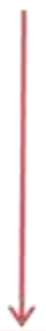

Occluded saphenous vein graft

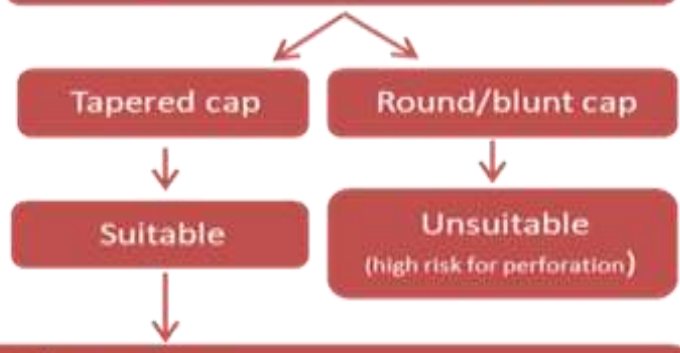

Use supportive guiding catheter

\section{Wire saphenous vein graft (SVG):}

If open: conventional wire

If occluded: polymer (jacket) wire (Fielder, Pilot, Gladius,...) + microcatheter (MC)

SVG ends distal to CTO segment<smiles>C1C2CC1C2</smiles>

Wire reaches distal true lumen:

If graft is occluded $\rightarrow$ confirmed from collaterals If Braft is still open $\rightarrow$ confirmed from graft

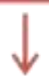

SVG ends proximal to CTO segment

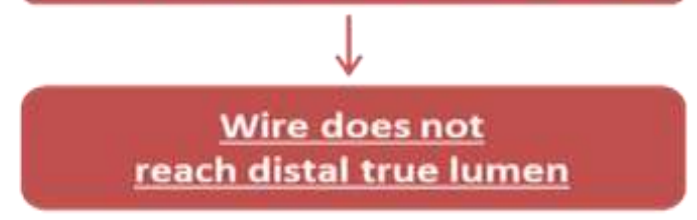

$\downarrow$

Retrograde (RWE/CART/reverse CART) applicable?

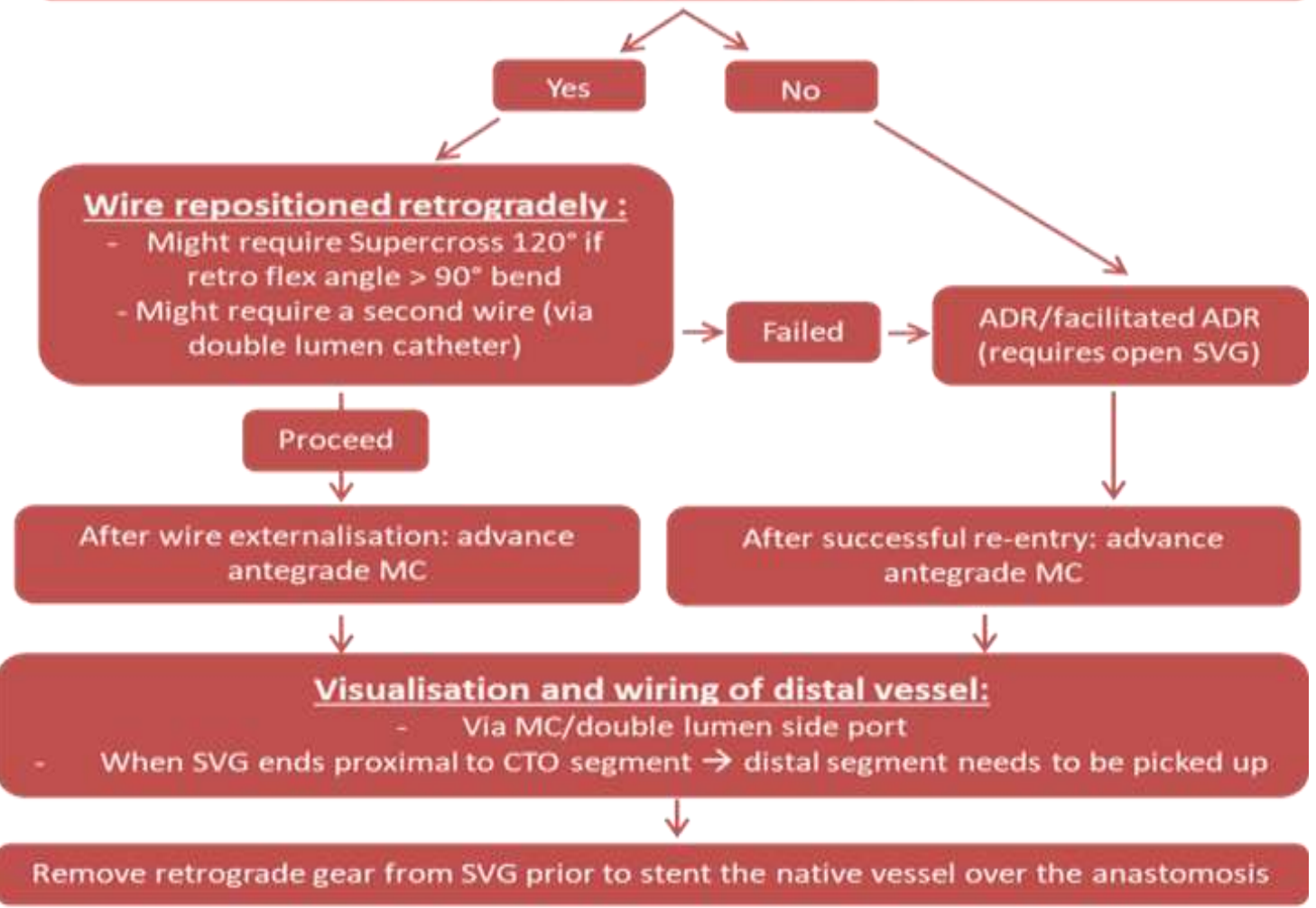

Figure 2: Specific strategy $(C T O=$ chronic total occlusion, $S V G=$ saphenous vein graft, $M C=$ microcatheter, AWE = antegrade wire escalation, $A D R=$ antegrade dissection re-entry, $R W E=$ retrograde wire escalation, $C A R T=$ controlled antegrade and retrograde tracking) 


\section{Case series}

The first case is a 73-year old male who presented with peri-operative ischemia during transurethral resection of the prostate (TURP). The electrocardiogram (ECG) showed diffuse ST-depression in all leads and ST-elevation in aVR with mildly elevated high-sensitive troponine T (19 ng/L, cut-off < 14). Transthoracic echocardiography (TTE) showed preserved left ventricle function (visual estimation about 60\%) with no regional contractility abnormalities.

The patient was known with diabetes mellitus, peripheral arterial disease and coronary artery bypass graft (CABG in 2002) with left internal mammary artery (LIMA) on the $2^{\text {nd }}$ lateral branch of the circumflex (L2Cx), right internal mammary artery (RIMA) on the left anterior descending artery (LAD) and saphenous venous graft (SVG) originating from the aorta to the right coronary artery (RCA). Coronary angiography showed patency of the LIMA-L2Cx and RIMA-LAD. There was a CTO of the RCA and also a CTO of the SVG to the RCA (duration of occlusion of SVG unknown). There were epicardial collaterals originating from the
Cx to the inferolateral (IL) branch from the RCA (Figure 3A).

Because of the presence of ischemia and preserved contractility of the inferior wall on TTE, CTO desobstruction was planned. Double arterial access was implemented with use of supportive guiding catheters. Contrast injection of the LIMA was performed by 6 French (Fr) IMA guiding catheter through the left radial artery. Contrast injection of the RCA was performed by 7 Fr AR II through the right femoral artery. Because of unsuitable interventional epicardial collaterals from $\mathrm{Cx}$ to the IL-branch, we switched from the LIMA to the occluded SVG (the SVG was injected by 6 Fr AL 0.75 guiding catheter).

The first step is to "blindly" wire the SVG towards the native coronary artery (Figure 3B $+\mathbf{C}$ ) by using a polymer jacket wire and MC. To confirm the wire being in the distal true lumen, visualization of the distal target via collaterals from the other branches is needed. This is confirmed by contrast injection in the donor artery (double access and in selected cases triple access is needed). Here, the SVG is wired using a Pilot 200 (Abbott, US) and Corsair MC (Asahi, Japan).

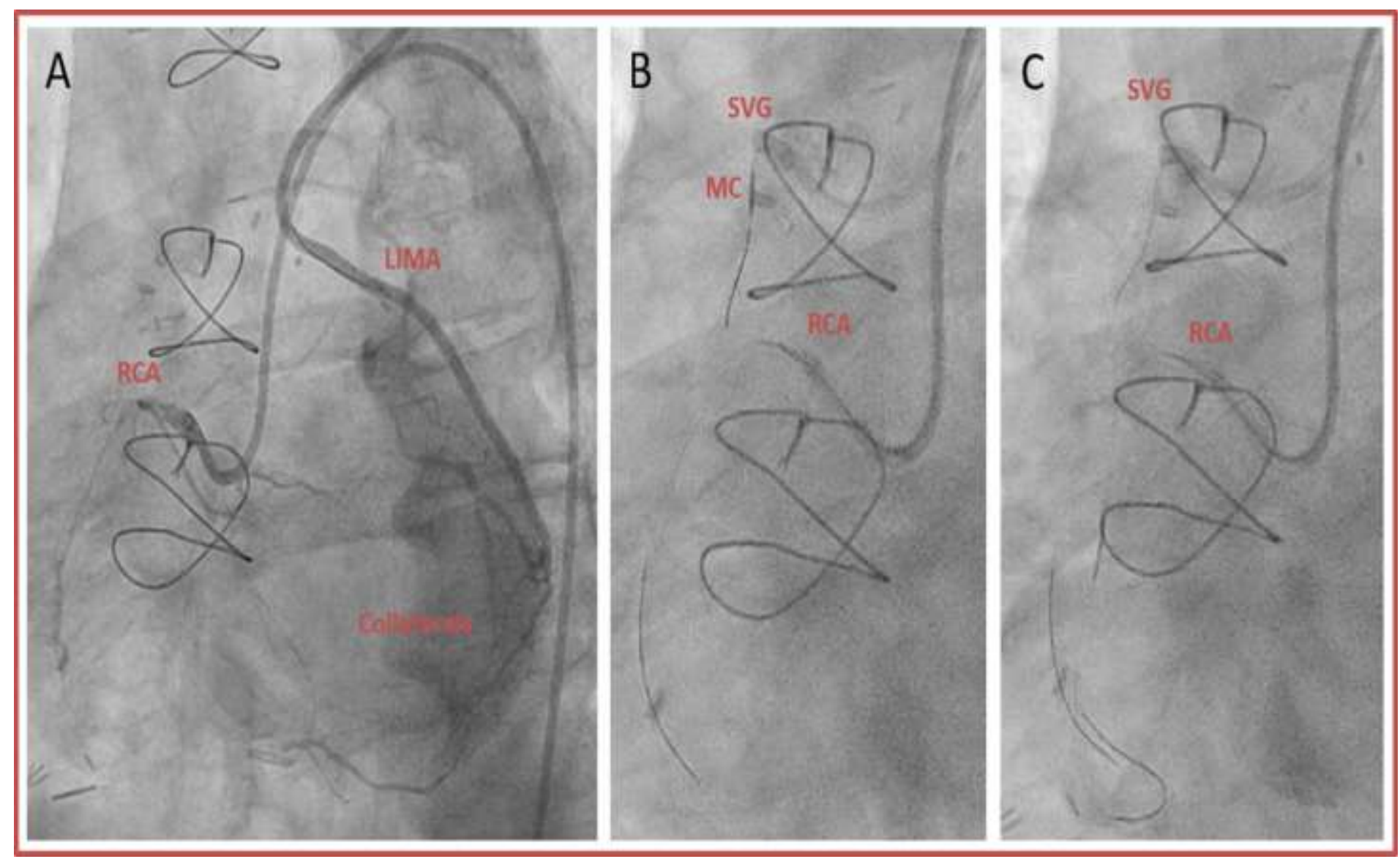

Figure 3A: CTO of the RCA and SVG to the RCA with epicardial collaterals. $\boldsymbol{B}+\boldsymbol{C}$. Wiring the SVG towards the RCA by polymer jacket wire and $M C$. $(C T O=$ chronic total occlusion, $R C A=$ right coronary artery, $S V G=$ saphenous vein graft, $M C=$ microcatheter $)$

After this, the native coronary artery is wired retrogradely from the SVG. Sometimes the SVG connects with a sharp angle and the use of Supercross $120^{\circ}$ (Teleflex, US) or double lumen MC is needed (Figure 4A). A double lumen catheter is advised if the SVG anastomosis is proximal from the distal cap. In this case, the native RCA was retrogradely wired through the SVG using a Gaia 3 (Asahi, Japan) and Corsair MC (Asahi, Japan).

If this is successful, the next step is retrograde wire escalation (RWE), reverse controlled antegrade and retrograde subintimal tracking (reverse CART) or CART. In this case, reverse CART was used (Figure 4B). First, balloon insufflation of the RCA was performed over the antegrade wire in the native RCA, followed by wiring of the created space with the retrograde wire. This wire enters the AR II guiding. The retrograde MC is also advanced into the AR II guiding, after which the retrograde wire is exchanged for a RG3 (Asahi, Japan) or R350 (Teleflex, US) wire (externalization) (Figure 4C). 


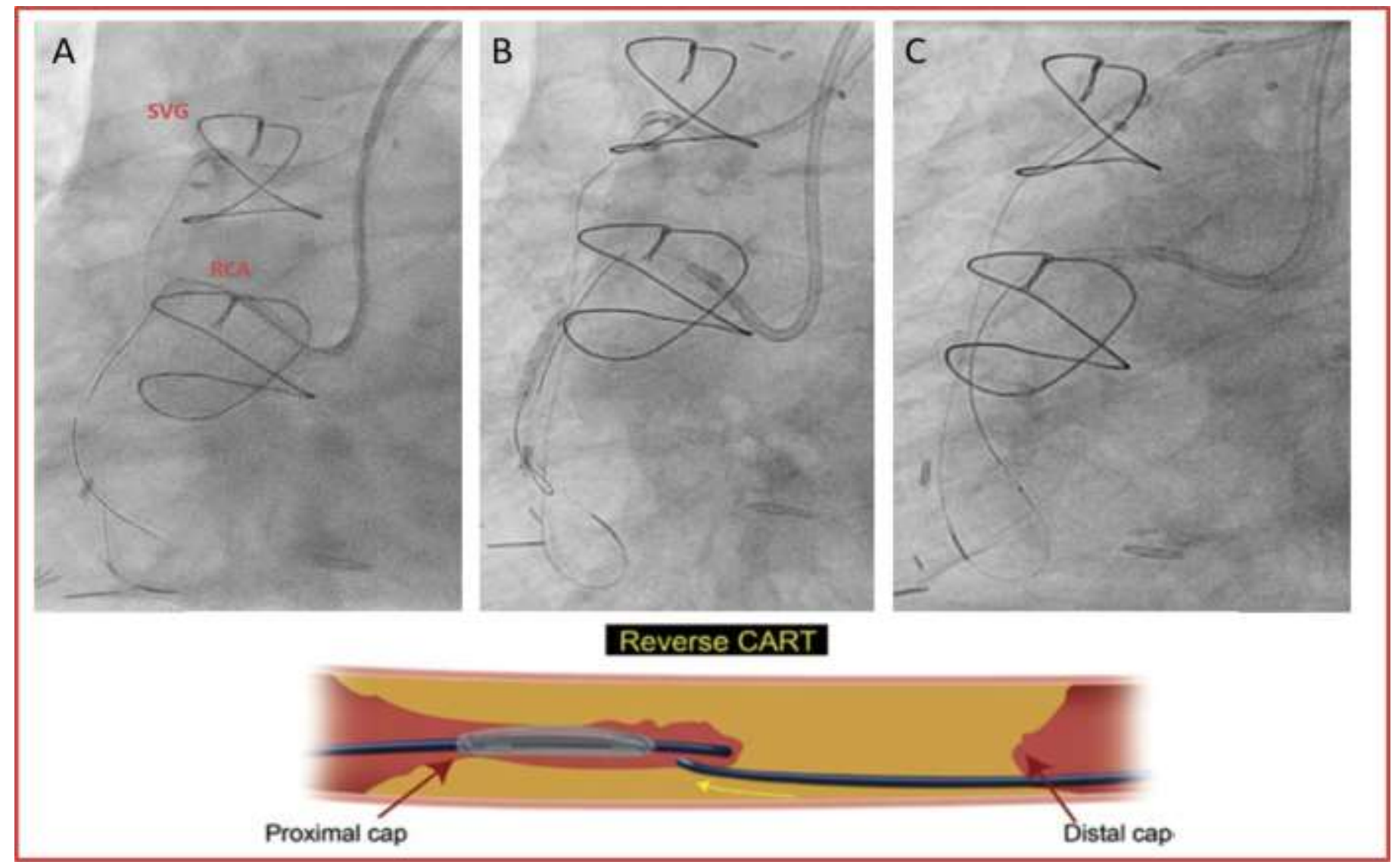

Figure 4A: Wiring the RCA retrograde through the SVG. B. Reverse CART. C. Externalization. $(R C A=$ right coronary artery, SVG = saphenous vein graft, $C A R T=$ controlled antegrade and retrograde tracking)

Lesion preparation with antegrade ballooning is performed over the externalized system (Figure $\mathbf{5 A}+\mathbf{B})$.

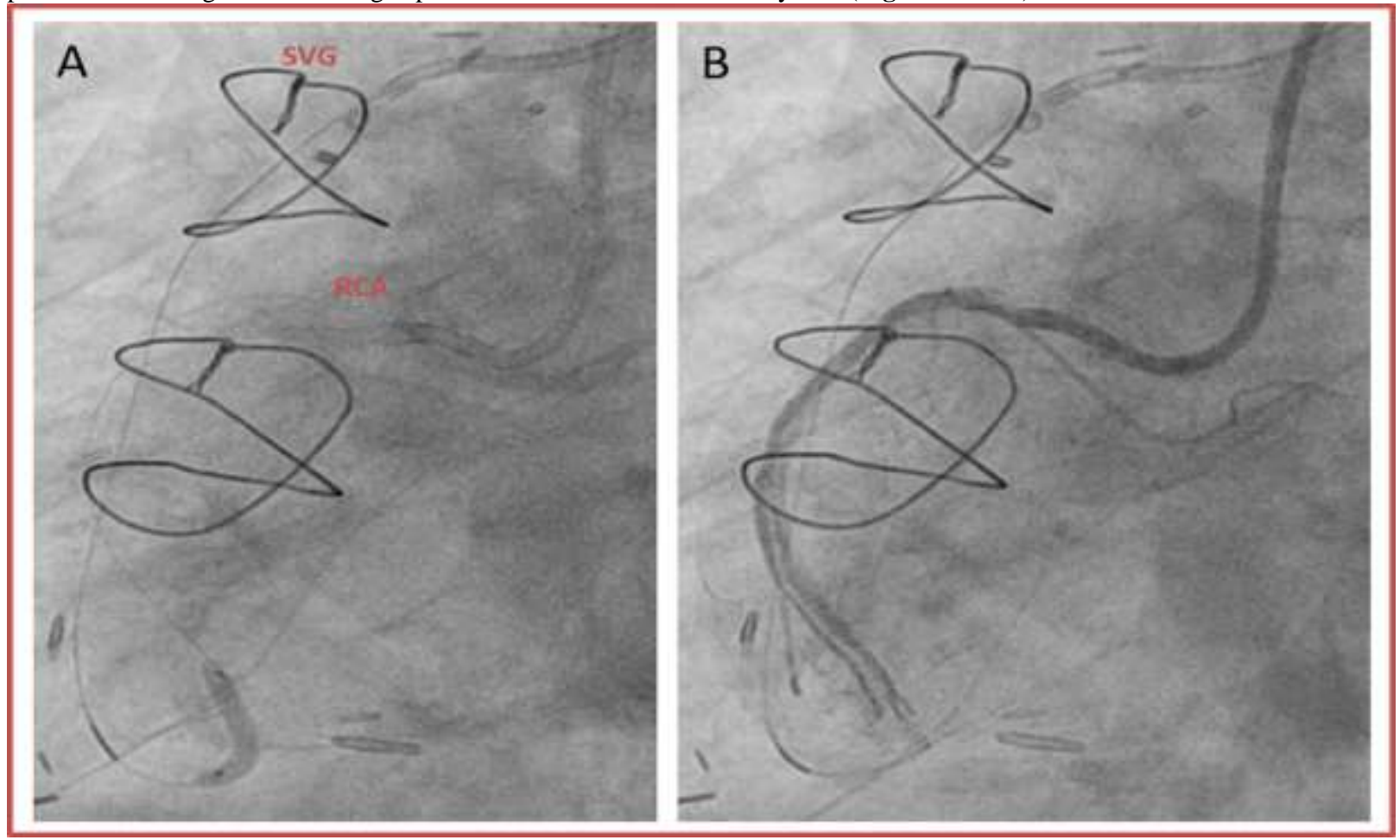

Figure 5. A + B: After externalization, antegrade lesion preparation (RCA = right coronary artery, SVG = saphenous vein graft) 
The final step is to visualize and wire the distal vessel, either through collaterals or through contrast injection with a microcatheter/double lumen side port (Figure 6A). Once an antegrade system is in place and has reached the distal vessel, the retrograde gear has to be removed to avoid jailing the retrograde wire with a stent. A Corsair MC (Asahi, Japan) and Sion Black (Asahi, Japan) were used to wire the distal portion of the vessel (the anastomosis of the occluded SVG was close to the distal cap). Pre-dilatation was again performed, followed by stenting with drugeluting stents $(2.5 \times 48 \mathrm{~mm}$ Xience Xpedition, Abbott, US in the distal portion of the RCA, $3.0 \times 48 \mathrm{~mm}$ Xience Xpedition in the mid and proximal portion and a $3.5 \times 15 \mathrm{~mm}$ Xience Xpedition in the ostium). The end result showed restoration of the antegrade flow in the RCA (TIMI III flow) (Figure 6B).
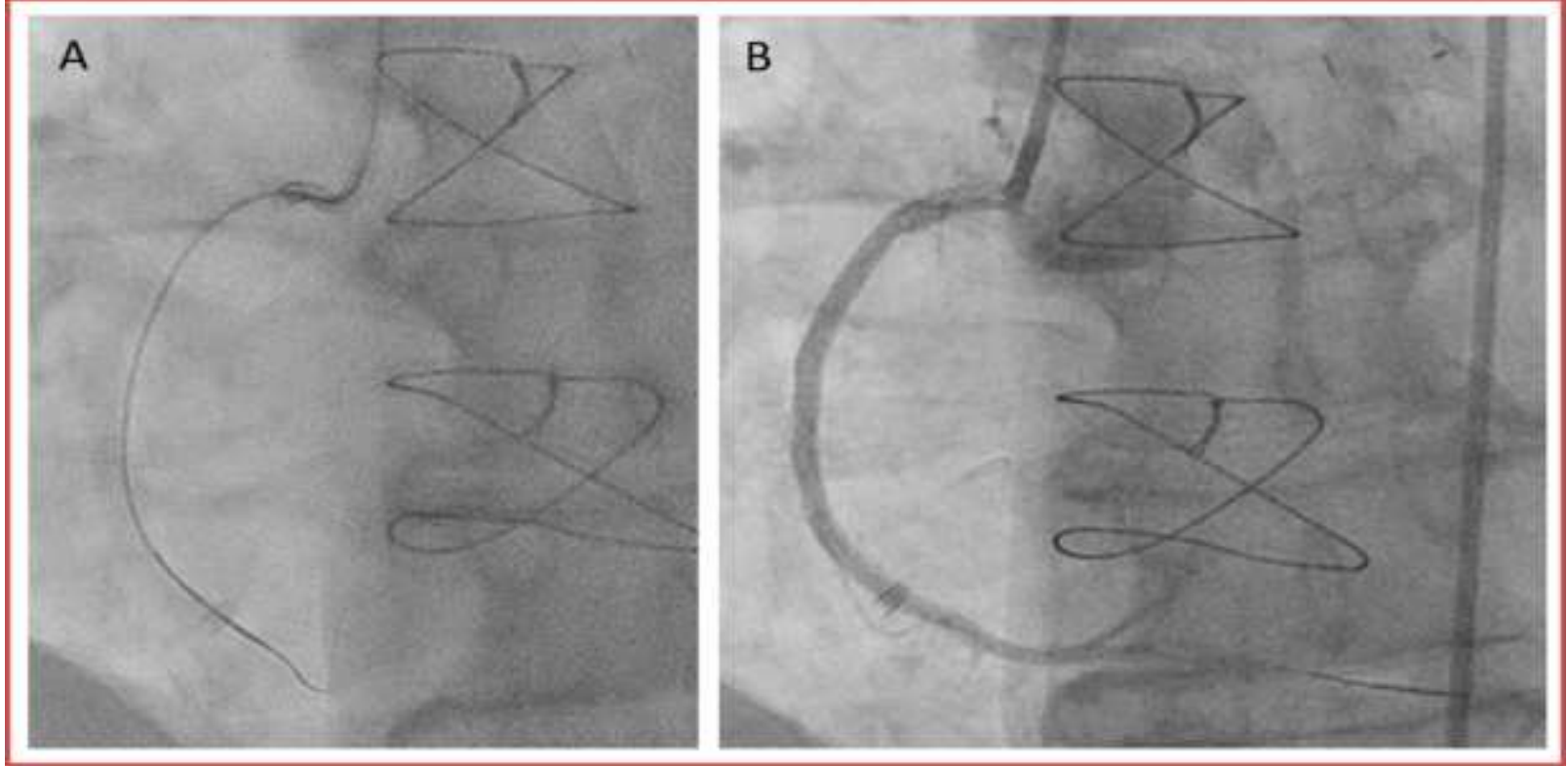

Figure 6A: Wiring the distal portion of the vessel. B. End result after stenting

The second case is a 78-year old male who presented with unstable angina (UA). He was known with a double chamber pacemaker (because of 3th degree atrio-ventricular block), transient ischemic attack and CABG (in 1999) with LIMA-LAD and SVG-RCA. The SVG had already been stented 5 months before this episode of UA (Orsiro, Biotronik, US $3.0 \mathrm{x}$ $13 \mathrm{~mm}$ in the mid segment + Orsiro $3.5 \times 15 \mathrm{~mm}$ in the proximal segment). Coronary angiography showed patency of the LIMA-LAD, CTO of the native RCA and occlusion of the SVG (occlusion of the stent in the proximal segment). There were collaterals originating from the septal branches to the posterior descending branch (PD) and inferolateral branch (IL) and also collaterals originating from the Cx to the IL branch (Figure 7).

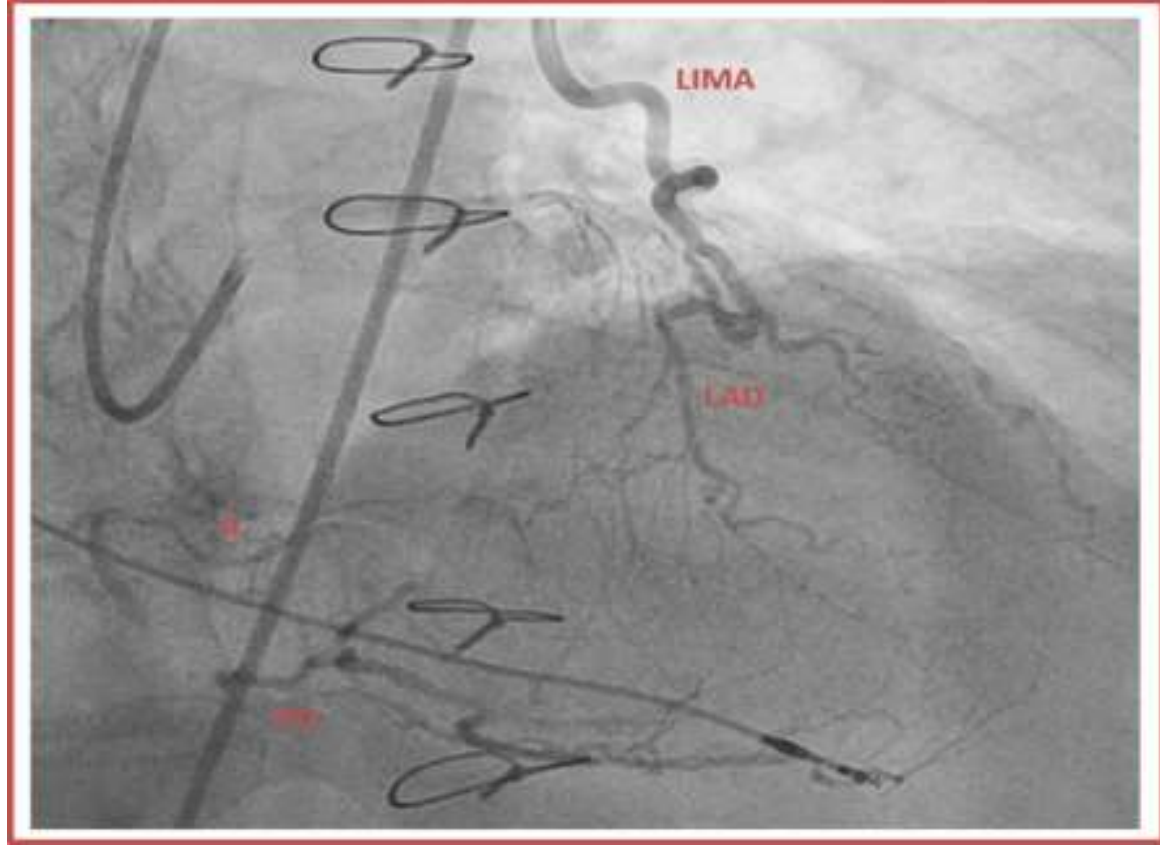

Figure 7. Patency of the LIMA-LAD, CTO of the native RCA and a CTO of the SVG with collaterals $($ LIMA = left internal mammary artery, LAD = left anterior descending artery, $C T O=$ chronic total occlusion, $S V G=$ saphenous vein graft, $I L=$ inferolateral branch, $P D=$ posterior descending artery) 
TTE showed preserved left ventricle function without regional contractility abnormalities. Because of the unstable angina and preserved contractility of the inferior wall on TTE, CTO desobstruction was planned.

Triple arterial access was implemented. Contrast injection of the LIMA was performed by 6 Fr IMA guiding catheter through the left radial artery. Contrast injection of the left main was performed by 6 Fr EBU 3.75 through the left femoral artery and the occluded SVG was injected by 6
Fr AL 0.75 guiding catheter through the right femoral artery. During the procedure, we switched the EBU 3.75 to a 7 Fr AR II guiding catheter for injection of the native RCA.

Following the same steps in the flowchart, the first step is to "blindly" wire the SVG towards the native coronary artery with visualization of the collaterals (Figure 8A). The next step is to wire the native coronary artery retrogradely through the SVG, here by using Caravel (Asahi, Japan) MC and Gaia 3 (Asahi, Japan) wire (Figure 8B).
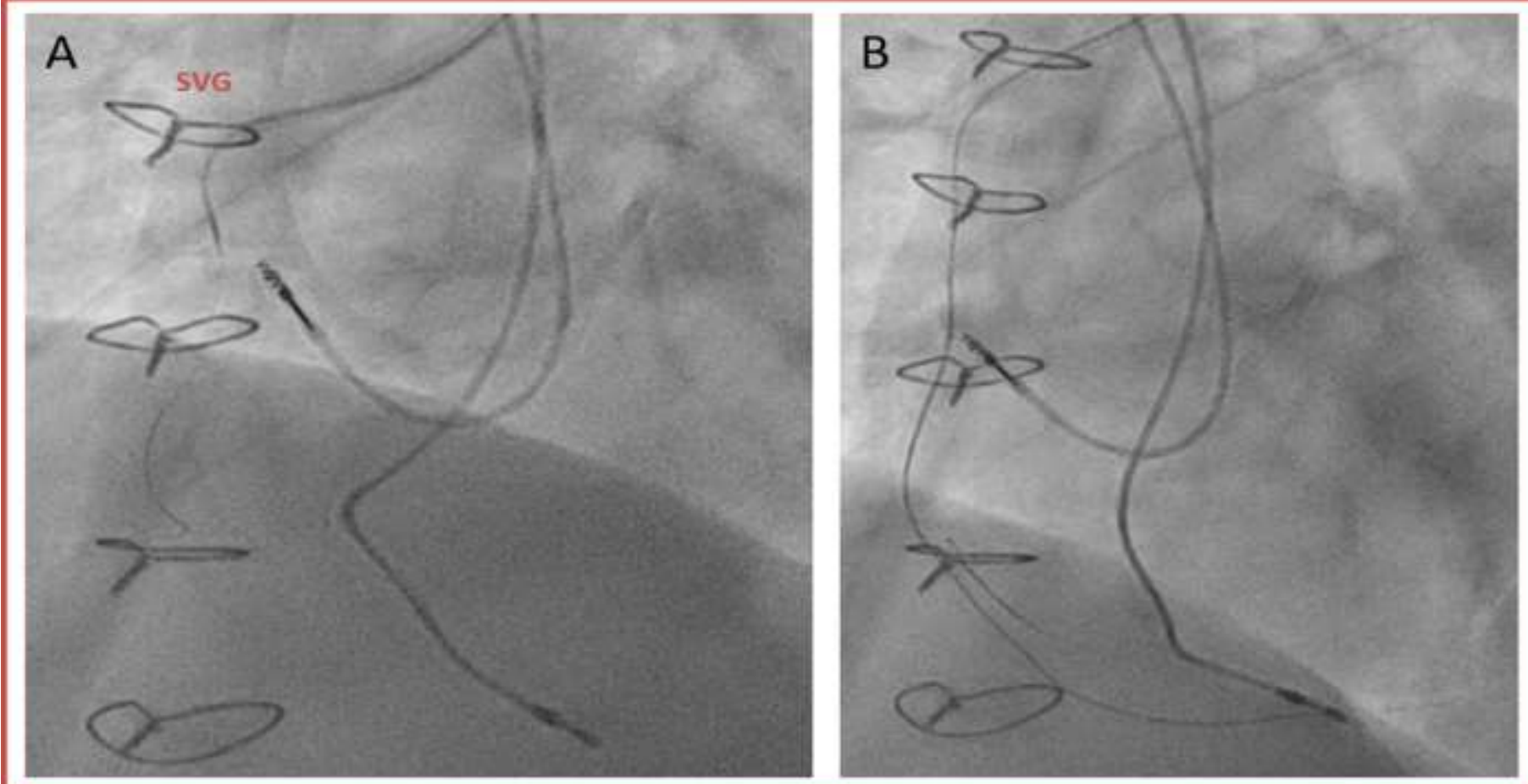

Figure 8A: "blindly" wiring of the SVG towards the RCA with previous visualization of the collaterals. B. Wiring of the RCA retrograde through the $S V G(R C A=$ right coronary artery, $S V G=$ saphenous vein graft $)$

The next step was reverse CART (Figure 9A) and externalization (Figure 9B).
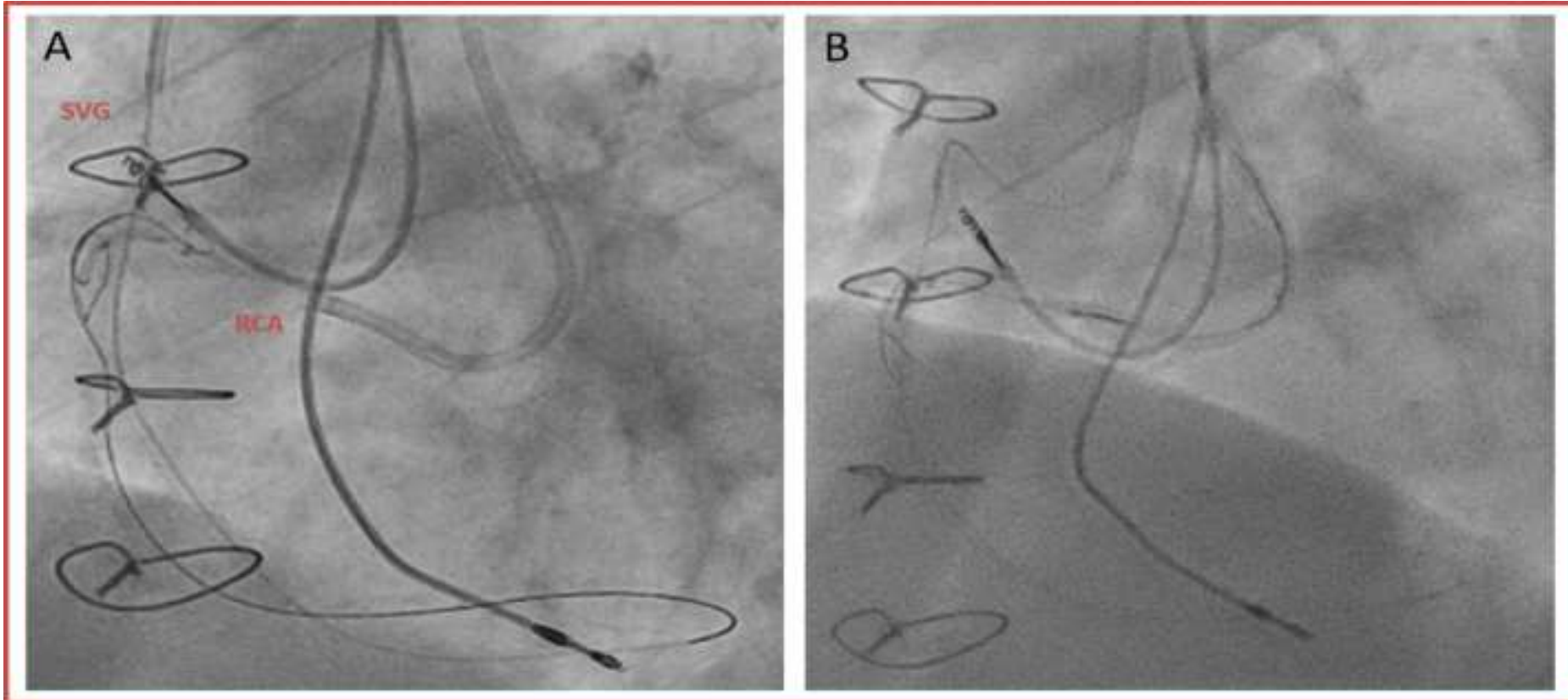

Figure 9A: Reverse CART. B. Externalization. (CART = controlled antegrade and retrograde tracking, $R C A=$ right coronary artery, SVG = saphenous vein graft) 
Lesions preparation (Figure 10A) and stenting of the mid and proximal segment (respectively 3.0 x 46 mm Cre8 Evo, Alvimedica, Italy +3.0 x 26 $\mathrm{mm}$ Cre8 Evo) was performed with restoration of the antegrade blood flow in the RCA (TIMI III flow) (Figure 10B).

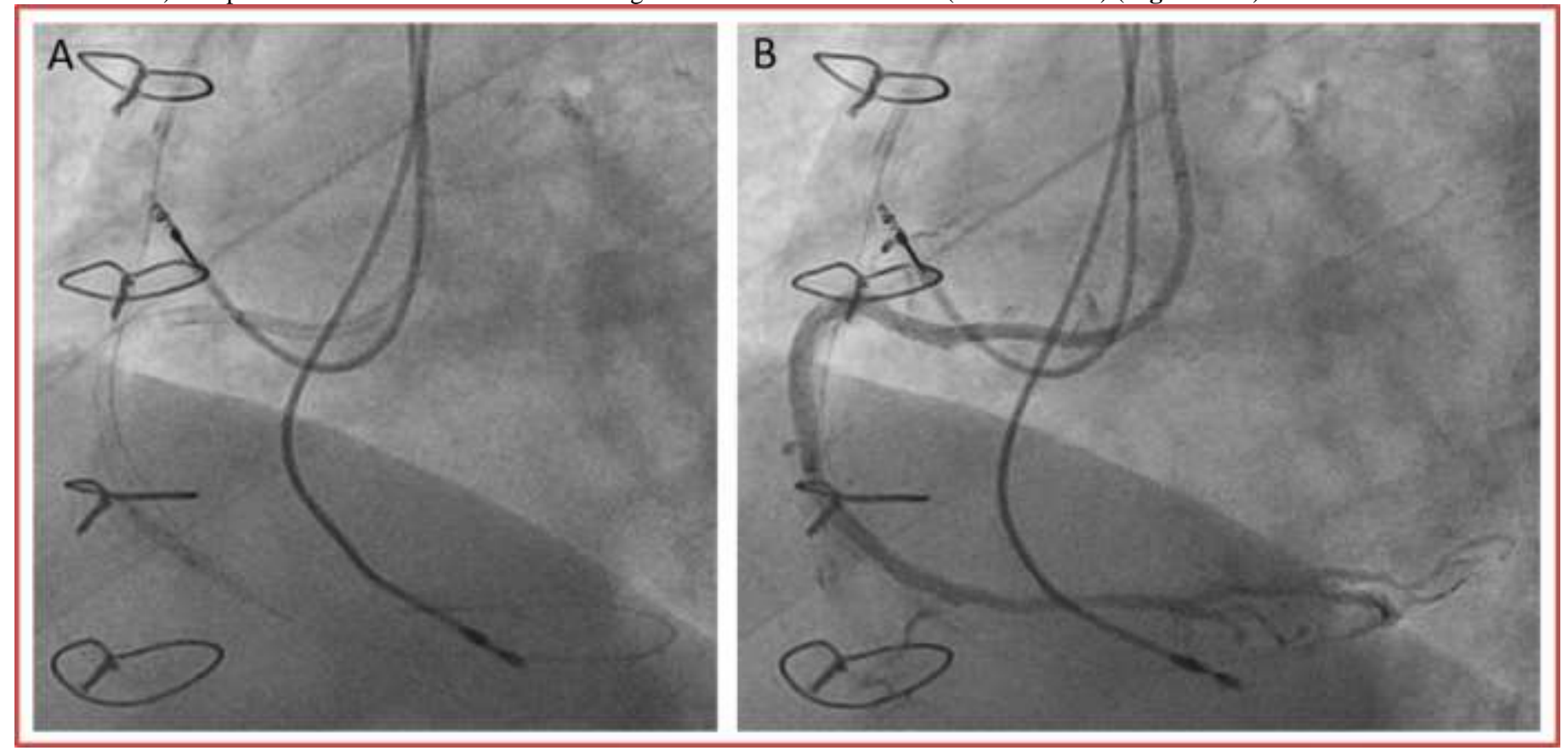

Figure 10A: Lesion preparation. B. Result after stenting.

The third case is a 72-year old male who presented with stable angina. He had a normal ECG without elevated cardiac markers. He was known with CABG (SVG-RCA and LIMA-LAD). TTE showed mildly depressed left ventricle function due to hypokinesia from the inferior wall. Coronary angiography showed a CTO of the RCA with a severely diseased SVG and poor retrograde filling from septal branches (Figure 11).

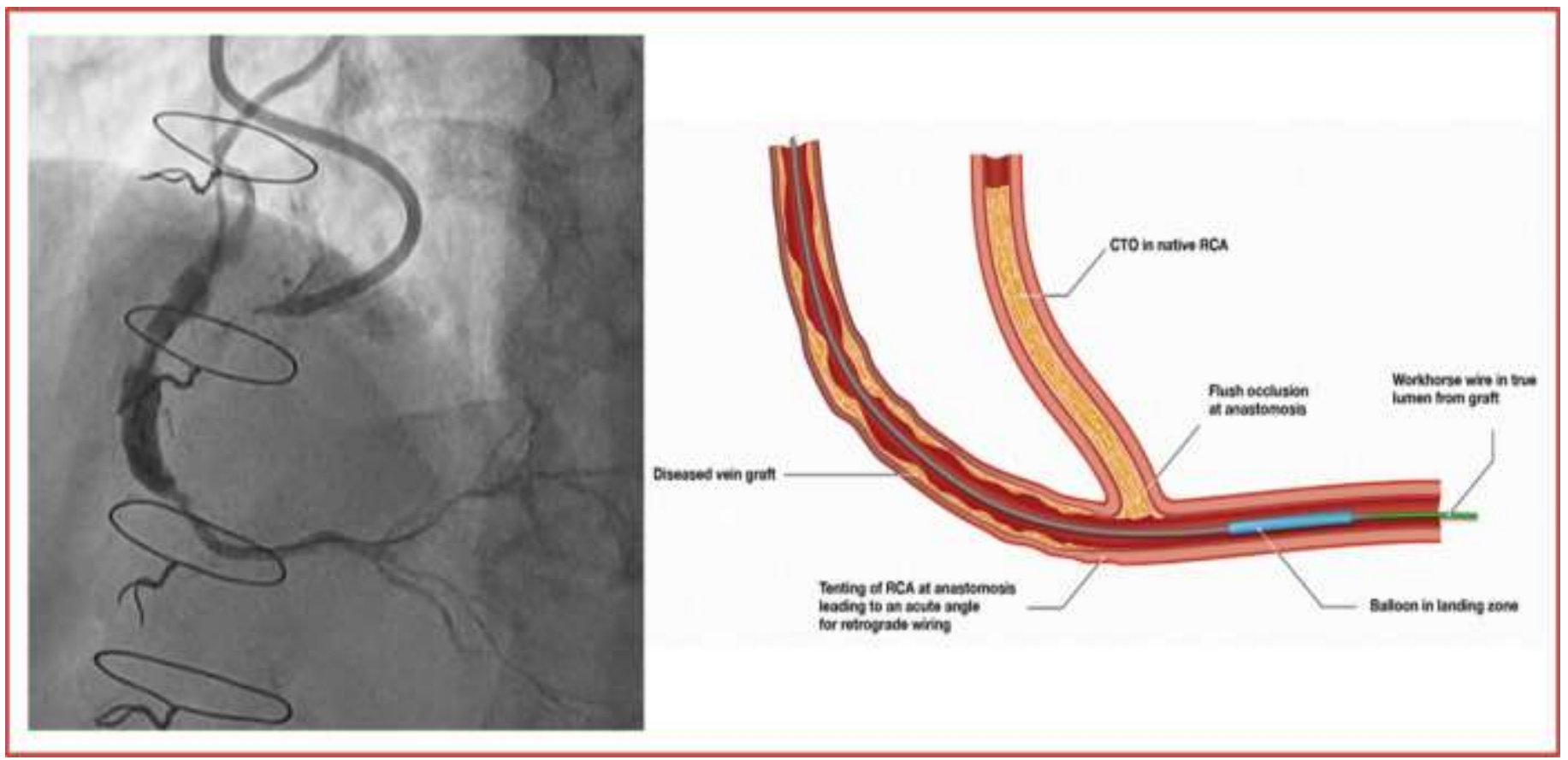

Figure 11. CTO RCA with wiring through severely diseased SVG $(C T O=$ chronic total occlusion, $R C A=$ right coronary artery, SVG = saphenous vein graft)

Double arterial access was implemented. Contrast injection of the SVG was performed by 6 Fr AL I guiding catheter through the right radial artery. Contrast injection of the RCA was performed by 7 Fr EBU 3.5 guiding catheter through the right femoral artery. Also following the same steps in the flowchart, the first step is to wire the SVG towards the native coronary artery. To connect the proximal cap with the distal vessel, the technique of facilitated ADR was used. A knuckle wire was used to dissect from the proximal CTO cap of the RCA beyond the graft anastomosis (Figure 12). 


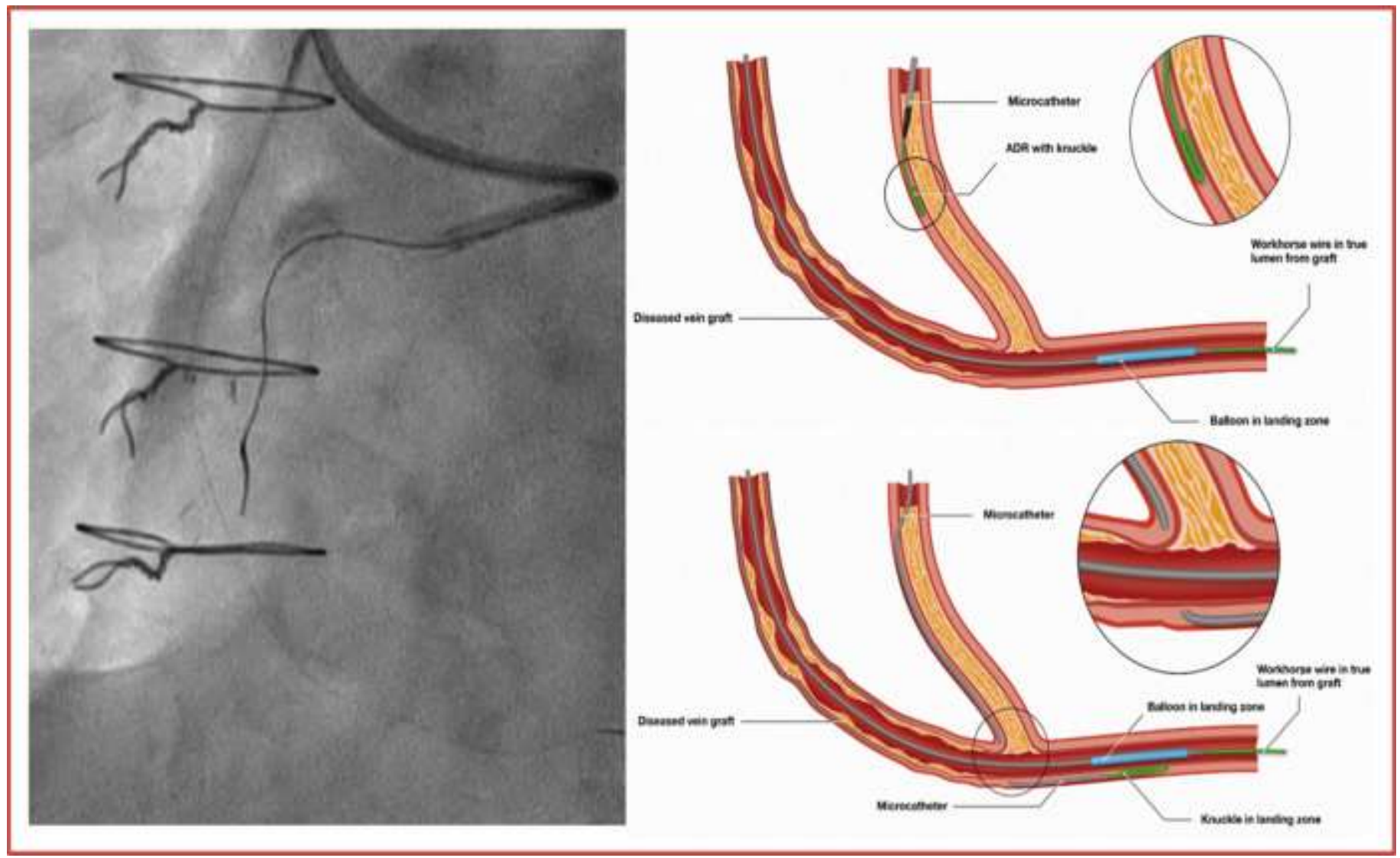

Figure 12. Antegrade knuckle wire $(A D R=$ antegrade dissection re-entry)

Re-entry from the subintimal space towards the true lumen was performed using the Stingray LP (Boston Scientific, US) at the distal RCA landing zone (beyond the graft anastomosis, but before the crux) (Figure 13).

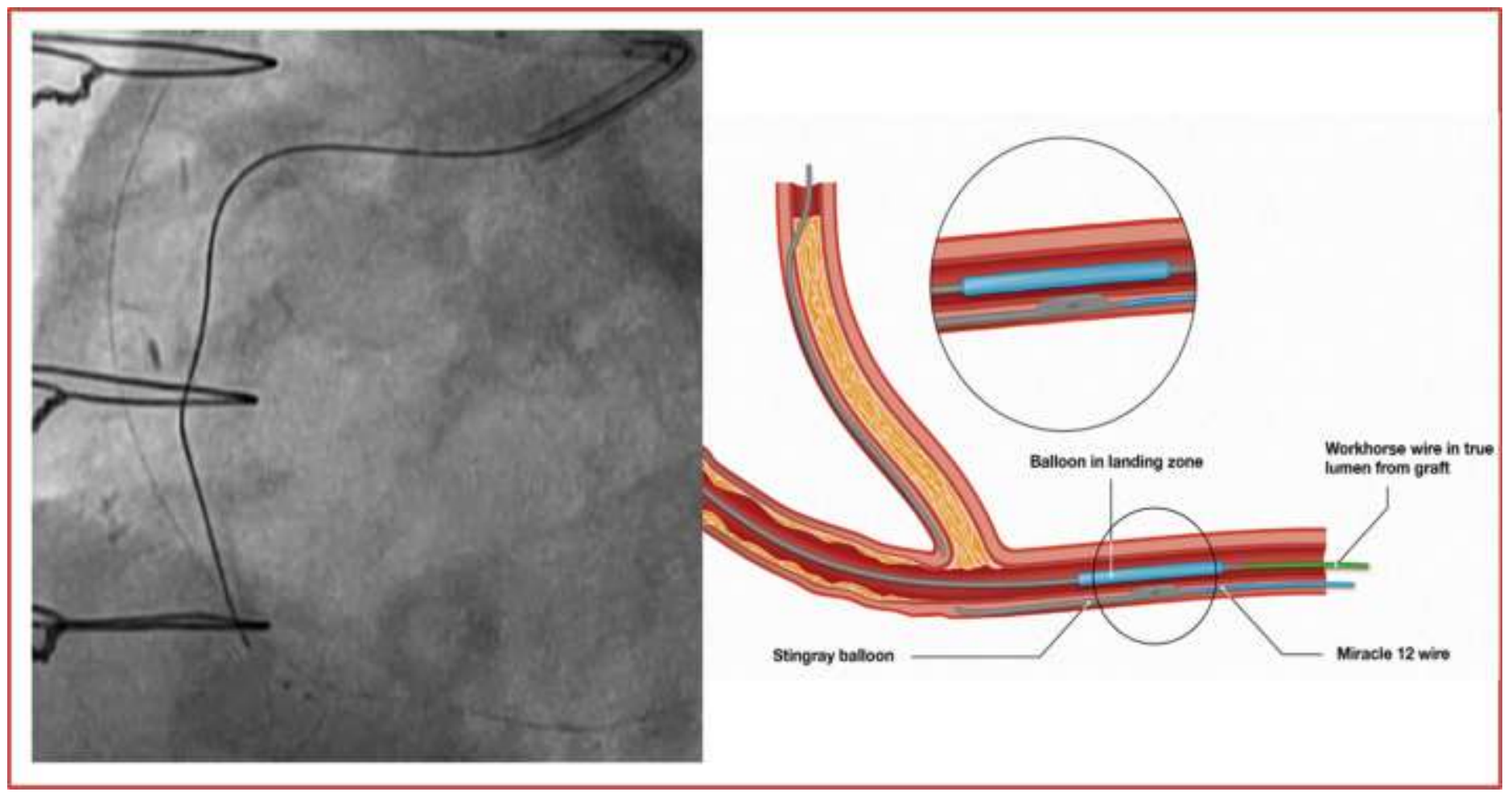


The re-entry was facilitated by a $3.0 \mathrm{~mm}$ compliant balloon via the SVG in the landing zone of the distal true lumen. This balloon is inflated to maximize the target for re-entry by using the Stingray wire (Boston Scientific, US) (Figure 14).

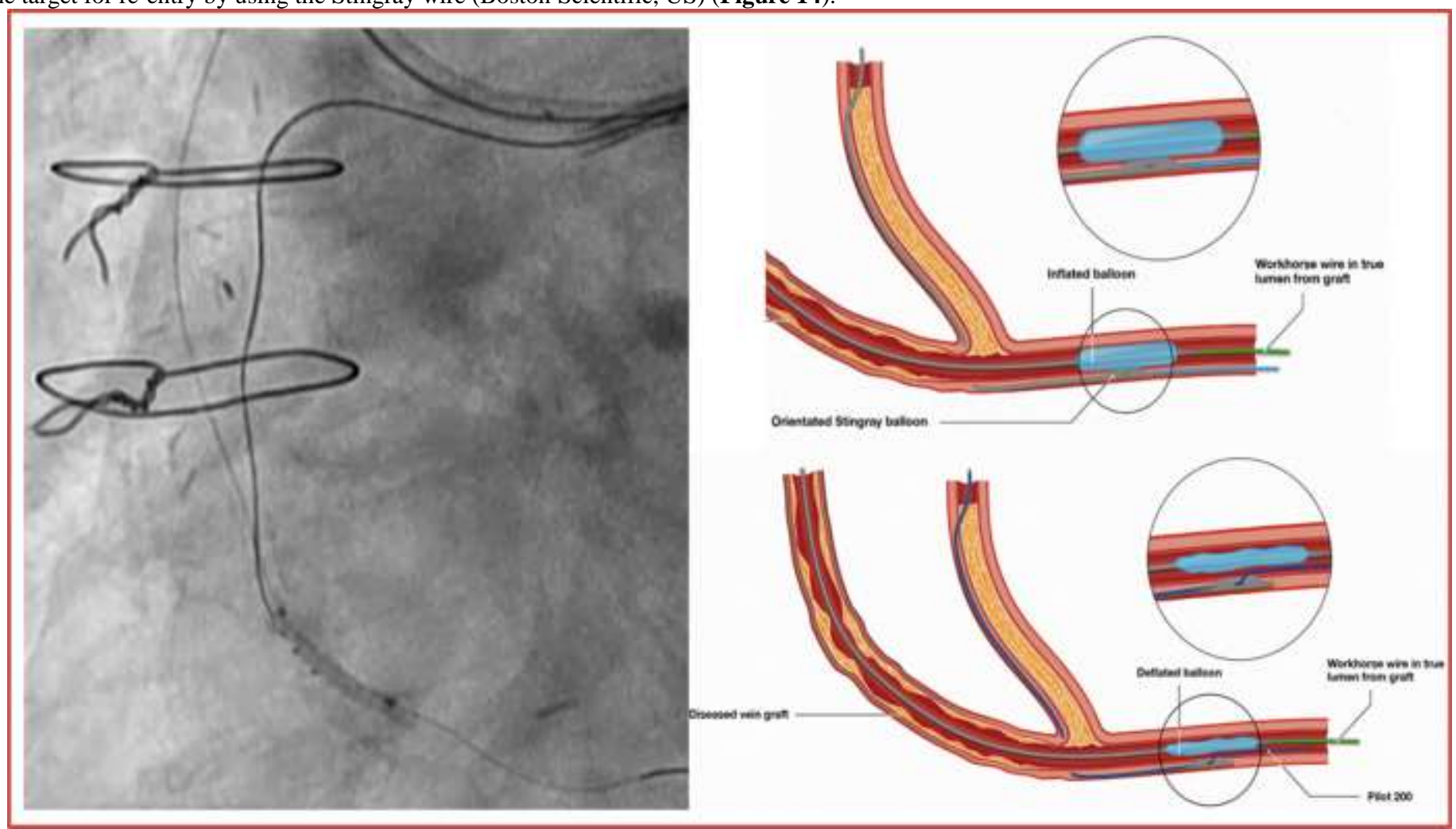

Figure 14: Re-entry with compliant balloon

Next, the $3.0 \mathrm{~mm}$ balloon is deflated and the Stingray wire can puncture and be advanced through the tissue plane towards the true lumen. After penetration in the true lumen, this wire was exchanged for a Pilot 200 wire (Abbott, US) to wire the distal portion of the RCA (stick and swap technique). Finally, lesion preparation and stenting of the RCA was performed (3.0 x $48 \mathrm{~mm}+3.5 \times 30 \mathrm{~mm}$, Synergy, Boston Scientific, US) (Figure 15).

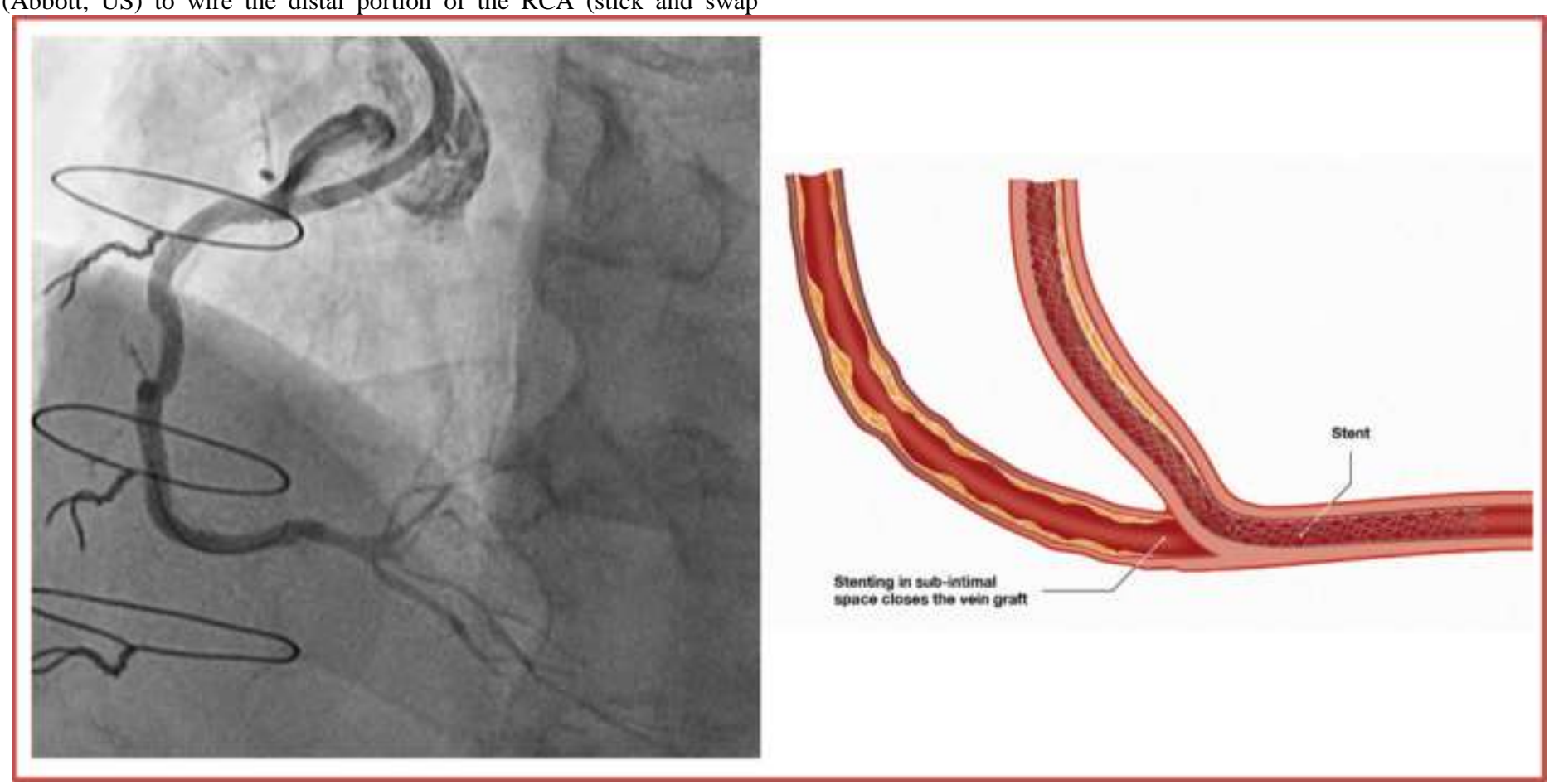

Figure 15: Final result after stenting native $R C A(R C A=$ right coronary artery) 


\section{Discussion}

Total coronary arterial bypass grafting $(\mathrm{CABG})$ provides better outcome then internal mammary artery (IMA) in combination with saphenous vein grafts (SVGs) [7]. Nevertheless, CABG with SVGs is still widely applied. SVGs will develop over time more atherosclerosis and will be occluded in $50 \%$ of the cases in 10 years' time post CABG [8]. Native coronary arteries also show accelerated atherosclerosis in post CABG patients [9] and therefore new CTOs could originate.

The three conventional techniques of CTO PCI remains the basis, but a retrograde approach through the SVG is suitable. Literature on retrograde CTO recanalization through a SVG is limited $[10,11]$. More recently, a larger United States (U.S.) registry was published [12].

Dautov et al [10] studied the outcome of CTO PCI through a SVG in 175 patients. Retrograde approach using a SVG was performed in $19 \%$ of the patients and through different collaterals in $36 \%$. Antegrade approach was performed in $45 \%$ of the patients. The use of either patent of occluded SVGs was associated with a higher success compared with other collateral channels (97\% vs $86 \%$; $\mathrm{p}=0.02)$. The final technical success was similar among the 3 different groups: $94 \%, 84 \%$ and $94 \%$ respectively for retrograde approach through SVGs, retrograde approach through other collateral channels and antegrade approach.

Nguyen-Trong et al. retrospectively reviewed retrograde CTO PCI through SVG in 21 patients. Procedural success rate was $86 \%$ in patients in whom retrograde SVG crossing was successful.

Recently Xenogiannis et al presented their data of PROGRESS-CTO (Prospective Global Registry for the Study of Chronic Total Occlusion Intervention). In this multicenter U.S. registry, 1615 patients were included with comparison of CTO PCI through a SVG (189 patients) versus other collaterals (1426 patients) [12]. The registry showed that the use of SVGs for retrograde crossing was associated with higher rates of procedural success $(81 \%$ vs. $74 \% ; \mathrm{p}=0.04)$ and no difference in inhospital major adverse cardiac events $(6.4 \%$ vs. $4.4 \%$; $=0.22)$ in comparison with retrograde CTO PCI through other collaterals. Moreover, they also report that SVGs are used as collateral conduits in $11.7 \%$ of the retrograde PCIs, which is less in Europe and Japan (3.9\% to $8.2 \%$ ).

Post CABG patients represent an important portion of the CTO procedures. In Japan, these number is relatively low (9.7\%) [13]. In Europa it is intermediate (17\%) [14] and in the United States high (36.5 $\%)$ [15].

$\mathrm{J}$-CTO score in post CABG patients is higher, making the procedure more complex. But, it's worth of investment for treating the native coronary arteries because of the poor rate of patency success of SVG on the long term [8]. PCI of SVGs is associated with poor long-term results and higher event rates [16].

The ongoing multicenter and randomized PROCTOR (Percutaneous Coronary Intervention of the native coronary artery versus venous bypass graft in patients with Coronary Artery Bypass graft) study will provide new insights in recanalization of the native coronary artery versus recanalization of the SVG in post CABG patients.

\section{Conclusion}

Despite all the different techniques which can be used for CTO desobstruction in post $\mathrm{CABG}$ patients, the complexity remains. Retrograde crossing of a SVG for native CTO PCI is associated with high rates of success, but is challenging. Therefore we propose a flowchart with algorithm for practical guidance.

\section{Declaration of conflict of interest:}

No potential conflict of interest was reported by the authors.

\section{References}

1. Kahn JK and Hartzler GO. Retrograde coronary angioplasty of isolated arterial segments through saphenous vein bypass grafts. Cathet Cardiovasc Diagn 1990; 20: 88-93.

2. Teramoto T, Tsuchikane E, Matsuo H, Suzuki Y, Ito T, Ito T, Habara M, et al. Initial success rate of percutaneous coronary intervention for chronic total occlusion in a native coronary artery is decreased in patients who underwent previous coronary artery bypass graft surgery. JACC Cardiovasc Interv 2014; 7: 39-46.

3. Fefer P, Knudtson ML, Cheema AN, Galbraith PD, Osherov AB, Yalonetsky S, et al. Current perspectives on coronary chronic total occlusions: the Canadian Multicenter Chronic Total Occlusions Registry. J Am Coll Cardiol 2012; 59: 991-997.

4. Galassi AR, Sianos G, Werner GS, Escaned J, Tomasello SD, Boukhris M, et al. Retrograde recanalization of chronic total occlusions in Europe: procedural, in-hospital, and long-term outcomes from the multicenter ERCTO registry. J Am Coll Cardiol 2015; 65: 2388-2400.

5. El Sabbagh A, Patel VG, Jeroudi OM, Michael TT, Alomar ME, Mogabgab $\mathrm{O}$, et al. Angiographic success and procedural complications in patients undergoing retrograde percutaneous coronary chronic total occlusion interventions: a weighted metaanalysis of 3,482 patients from 26 studies. Int J Cardiol 2014; 174: 243-248.

6. Brilakis ES, Karmpaliotis D, Patel V and Banerjee S. Complications of Chronic Total Occlusion Angioplasty. Interv Cardiol Clin 2012; 1: 373-389.

7. Chikwe J, Sun E, Hannan EL, Itagaki S, Lee T, Adams DH and Egorova NN. Outcomes of Second Arterial Conduits in Patients Undergoing Multivessel Coronary Artery Bypass Graft Surgery. J Am Coll Cardiol 2019; 74: 2238-2248.

8. Tatoulis J, Buxton BF and Fuller JA. Patencies of 2127 Arterial to Coronary Conduits Over 15 Years. Ann Thorac Surg 2004; 77: 93-101.

9. Pereg D, Fefer P, Samuel M, Wolff R, Czarnecki A, Deb S, et al. Native Coronary Artery Patency After Coronary Artery Bypass Surgery. JACC Cardiovasc Interv 2014; 7: 761-767.

10. Dautov R, Nguyen CM, Altisent O, Gibrat C and Rinfret S. Recanalization of Chronic Total Occlusions in Patients With Previous Coronary Bypass Surgery and Consideration of Retrograde Access via Saphenous Vein Grafts. Circ Cardiovasc Interv 2016; 9.

11. Nguyen-Trong PK, Alaswad K, Karmpaliotis D, Lombardi W, Grantham JA, Lembo N, et al. Use of Saphenous Vein Bypass Grafts for Retrograde Recanalization of Coronary Chronic Total Occlusions: Insights From a Multicenter Registry. J Invasive Cardiol 2016; 28: 218-224.

12. Xenogiannis I, Gkargkoulas F, Karmpaliotis D, Krestyaninov O, Khelimskii D, et al. Retrograde Chronic Total Occlusion Percutaneous Coronary Intervention via Saphenous Vein Graft. JACC Cardiovasc Interv 2020;13: 517-526.

13. Suzuki Y, Tsuchikane E, Katoh O, Muramatsu T, Muto M, Kishi $\mathrm{K}$, et al. Outcomes of Percutaneous Coronary Interventions for Chronic Total Occlusion Performed by Highly Experienced Japanese Specialists: The First Report From the Japanese CTOPCI Expert Registry. JACC Cardiovasc Interv 2017; 10: 21442154.

14. Maeremans J, Walsh S, Knaapen P, Spratt JC, Avran A, Hanratty $\mathrm{CG}$, et al. The Hybrid Algorithm for Treating Chronic Total 
Occlusions in Europe: The RECHARGE Registry. J Am Coll Cardiol 2016; 68: 1958-1970.

15. Sapontis J, Salisbury AC, Yeh RW, Cohen DJ, Hirai T, Lombardi W, et al. Early Procedural and Health Status Outcomes After Chronic Total Occlusion Angioplasty: A Report From the OPENCTO Registry (Outcomes, Patient Health Status, and Efficiency in
Chronic Total Occlusion Hybrid Procedures). JACC Cardiovasc Interv 2017; 10: 1523-1534.

16. Maleki ND, Afshar AE and Parikh PB. Management of Saphenous Vein Graft Disease in Patients With Prior Coronary Artery Bypass Surgery. Curr Treat Options Cardiovasc Med 2019; 21: 12.

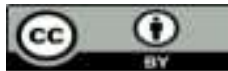

This work is licensed under Creative Commons Attribution 4.0 License

To Submit Your Article Click Here: Submit Manuscript

DOI: $10.31579 / 2641-0419 / 134$
Ready to submit your research? Choose Auctores and benefit from:

* fast, convenient online submission

* rigorous peer review by experienced research in your field

* rapid publication on acceptance

* authors retain copyrights

* unique DOI for all articles

* immediate, unrestricted online access

At Auctores, research is always in progress.

Learn more www.auctoresonline.org/journals/clinical-cardiology-andcardiovascular-interventions 